\title{
Fine needle aspiration cytology of primary sphenoid sinus esthesioneuroblastoma metastatic to the skin
}

\author{
Josephine Akinfolarin, Tarek Jazaerly, Kia Jones ${ }^{1}$, Maher Abu-Hamdan, , Fulvio Lonardo, Adam Folbe ${ }^{1}$, Tamar Giorgadze
} Departments of Pathology, and '1Otolaryngology, Wayne State University, Detroit Medical Center, Detroit, MI, USA

\begin{tabular}{|c|}
\hline Access this article online \\
\hline Website: www.avicennajmed.com \\
\hline DOI: 10.4103/2231-0770.94806 \\
\hline Quick Response Code: \\
$\square$ \\
\hline
\end{tabular}

\section{ABSTRACT}

Esthesioneuroblastoma (ENB) is a rare tumor derived from olfactory neuroepithelium. ENB in a site outside of where olfactory epithelium exists is exceedingly rare with only five cases of ENB isolated to the sphenoid sinuses described in the literature to date. To the best of our knowledge, a skin metastasis of ENB outside the head and neck region has not been reported. We present an unusual case of a 33-year-old male diagnosed with primary sphenoid sinus ENB, who underwent surgical resection of the tumor followed by chemoradiation. About 5 months later, the patient developed a dermal mass in the sternal region, clinically suspicious for metastasis. Fine needle aspiration (FNA) revealed a tumor with morphological features and immunophenotype consistent with the metastasis from patient's known primary sphenoid sinus ENB. Our case demonstrates that the skin may be a rare site of a metastatic ENB, and FNA is a cost-effective and reliable diagnostic method of a suspected cutaneous metastasis.

Key words: Esthesioneuroblastoma, metastasis, skin

\section{INTRODUCTION}

Esthesioneuroblastoma (ENB) is a rare tumor derived from olfactory neuroepithelium. It was first described in 1924 by Berger and Richard as L’esthésioneuroépithéliomeolfact if. ${ }^{[1]}$ These tumors account for 3-6\% of all intranasal tumors and just $1 \%$ of the malignant lesions. ${ }^{[2,3]}$ The occurrence of ENB in a site outside of where olfactory epithelium exists is exceedingly rare. Isolated ENB has been described in the ethmoid sinus, maxillary sinus, nasopharynx, and pituitary gland. ${ }^{[4-6]}$ Only five cases of ENB isolated to the sphenoid sinuses have been described in the literature to date. ${ }^{[7-9]}$ To the best of our knowledge, skin metastases of ENB outside of the head and neck region have not been previously reported. We present fine needle aspiration (FNA) findings of sphenoid sinus ENB that metastasized to the sternal chest wall.

\section{CASE REPORT}

The patient was a 33-year-old male who presented to the emergency department with double vision, headache, and a 3-month history of chronic sinusitis unresponsive to multiple courses of antibiotics. The ENT examination revealed tenderness over the left frontal and maxillary sinuses, left cervical lymphadenopathy, left-sided sixth nerve palsy, and minimal hypersensitivity in all three sensory divisions of the left cranial nerve V. CT scans of the head and maxillofacial region revealed non-contrast enhancing soft tissue density opacities within the sphenoid sinuses, eroding the surrounding bony structures throughout the clivus and inferior aspect of the sella. Follow-up MRI of the brain and paranasal sinuses revealed a large heterogeneous mass filling the sphenoid sinuses. The patient underwent functional endoscopic sinus surgery with bilateral sphenoidotomies were performed. Intraoperatively, a brown-yellow, tenacious material was found within the sphenoid sinus. Frozen sections revealed abundant small blue cells, suspicious for lymphoma. Histopathologically, the tumor demonstrated morphologic features of so-called "small round blue cell tumor" with extensive necrosis and no obvious rosette formation. By immunohistochemistry, the tumor cells stained positive for synaptophysin and chromogranin and negative for multiple cytokeratins (AE1/ AE3, CAM5.2, CK7, CK20), epithelial membrane antigen (EMA), pituitary hormones, leukocyte common antigen

Address for correspondence: Dr. Tamar Giorgadze, Department of Pathology, Wayne State University, 3990 John R, Detroit, MI 48201 USA. E-mail: tgiorgad@med.wayne.edu 
(LCA), desmin, S-100, CD99, and myogenin. The combined morphologhical and immunohistochemical features were most compatible with the diagnosis of sphenoid sinus ENB [Figure 1].

The patient underwent three courses of chemotherapy followed by definitive chemoradiation. Five months later, he was noted to have a palpable dermal mass in the sternal region. The mass measured $1.5 \mathrm{~cm}$ in the diameter and was soft, non-tender.

FNA of the mass was performed. The aspirate smears (including two air dried and two alcohol fixed smears) and cell block preparations were highly cellular and showed small round blue cells with scant cytoplasm, dispersed singly and in small cell clusters, in the background of abundant necrosis. The nuclei of the preserved tumor cells were round to oval, with finely granular chromatin and inconspicuous nucleoli. Nuclear molding with crush artifact and paranuclear 'blue bodies' were noted. Numerous cells with apoptotic nuclei were also seen scattered in the background. No true rosette or Homer-Wright pseudorosette formation, neuropil, or lymphoglandular bodies were seen. By immunohistochemistry, the tumor cells showed strong staining for synaptophysin and focal staining for chromogranin [Figure 2]. The rest of the immunomarkers, including cytokeratins, EMA, LCA, CD99, S-100, desmin, myogenin were negative. The morphologic features and immunostaining profile of the tumor were consistent with metastasis of the patient's known sphenoid sinus ENB.

\section{DISCUSSION}

ENB is known to occur throughout all age groups affecting both men and women at equal rates without any racial predilection. Peak occurrence appears to be bimodal, with the first peak between the ages of 10 and 30 and the second between 50 and 70 years. ${ }^{[2,10]}$

The clinical features of ENB are dependent upon the site of origin of the tumor and the involvement of surrounding structures by the tumor. Most of these tumors are located within the superior nasal cavity with secondary extension into the paranasal sinuses, orbit, and brain along submucosal planes; thus, the presenting symptoms of ENB include nasal obstruction, epistaxis, anosmia, rhinnorhea, and headache. Proptosis, epiphora, diploplia, and retrobulbar pain occur with orbital extension. Patients with intracranial involvement may have increased intracranial pressure, which can lead to cranial nerve deficits, coma, and eventually death. ${ }^{[9-11]}$ ENB shows great variability in behavior. Some cases of the tumor represented an indolent growth pattern while others have been extremely aggressive, with death occurring within a few months after diagnosis. ${ }^{[12]}$ Metastases occur often, and in about $30 \%$ of the cases, cervical lymph nodes involvement is the most common. Metastatic disease to the brain, bone, lungs, viscera, trachea, and heart has also been reported. ${ }^{[13]}$ In general, the skin is an uncommon site of metastatic disease from visceral malignancy, and skin metastasis of ENB is even more uncommon. ${ }^{[14-16]}$ Local recurrence of tumor frequently occurs, most commonly within the first $2-3$ years after initial treatment.

Clinical examination using an endoscope usually reveals a polypoid mass in the superior part of the nasal vault. In our case however, this examination was normal because there was no nasal involvement of tumor. Imaging studies therefore played a pivotal role in the initial evaluation of our patient as well as tumor staging. CT and MRI were helpful for staging the tumor and planning its management. CT imaging in the axial and coronal planes provided useful information about bony involvement of tumor, while MR
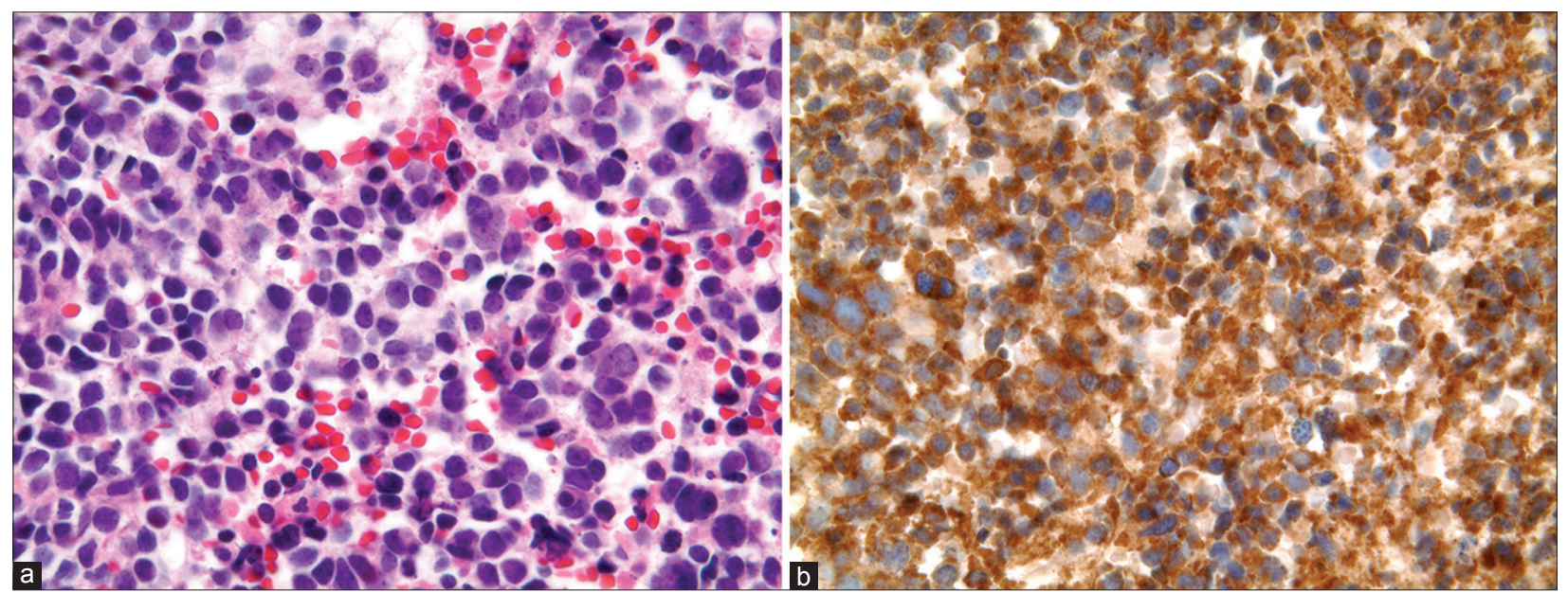

Figure 1: Primary sphenoid sinus esthesioneuroblastoma (ENB). (a) Tissue section demonstrating tumor with small blue round cell morphology (H and $E$, at $\times 20)$. (b) Positive immunostaining of the tumor for synaptophysin $($ at $\times 20)$ 


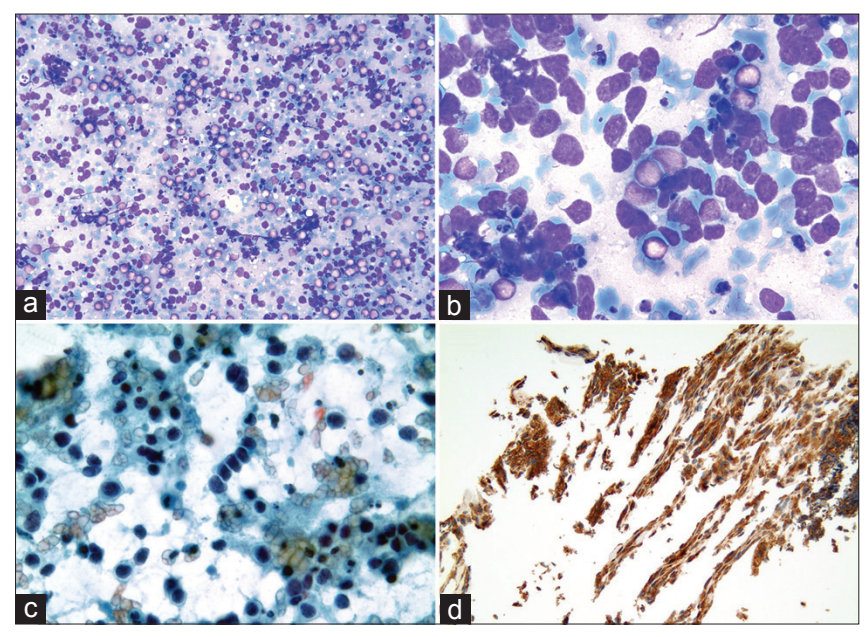

Figure 2: Fine needle aspiration specimen of the sternal mass with metastatic ENB. (a) Low power view of the air-dried smear showing high cellularity of the tumor with focal nuclear chromatin smearing and necrotic background (Diff-Quik stain, at $\times 20$ ). (b) High power view of the air-dried smear demonstrating two-cell population of the tumor: Large viable tumor cells with scant cytoplasm and nuclear molding and small tumor cells with apoptotic nuclei (Diff-Quik stain, at $\times 60$ ). (c) High power view of the alcohol-fixed smear demonstrating tumor cells scattered singly and in small clusters; note evenly dispersed nuclear chromatin (Pap stain, at $\times 60$ ). (d) Positive immunostaining for synaptophysin (cell block, at $\times 20$ )

imaging with contrast enhancement was used to characterize soft tissue extension. ${ }^{[17]}$

Several theories exist as to the origin of ENB in locations where olfactory neuroepithelium is not thought to exist. One theory is that ectopic cell nests are deposited in these areas (maxillary sinuses, ethmoid sinuses, pituitary gland, and sphenoid sinuses) during embryologic development. ${ }^{[18]}$

A second possible theory was first suggested by Jakumeit in 1971. ${ }^{[19]}$ This theory is based on the development and degeneration of the accessory olfactory systems during fetal life. The cells of these accessory systems eventually degenerate in fetal life. Persistence of these cells may be the origin of ENB occurring in these sites.

Histopathology is extremely important in the diagnosis of ENB, and histological grade functions as an important prognostic indicator. The grading criteria for ENB is based on Hyams classification which looks at the degrees of tumor necrosis, mitotic activity, preservation of tissue architecture, and the presence of a fibrillar matrix and rosette formation, and correlates these microscopic findings to clinical outcomes. ${ }^{[15,20]}$ The morphologic features are similar to other small cell tumors of the neuroectodermal origin.

The majority of ENBs stain positive for CD56, neuronspecific enolase, chromogranin, synaptophysin, and the sustentacular cells stain positive for S-100 protein..$^{[15,16,20]}$ Most ENBs are negative for cytokeratins and EMA. ENB shows morphologic variability including a wide spectrum of grade, histology, and immunophenotype diversity. ${ }^{[20]}$

The tumor in our patient was a high-grade neoplasm. Rare cases of high-grade ENB with negative staining for S-100 have been described, as in our case.

Cytologic features of ENB have been well described in the literature. To date, eighteen cases have been reported, the majority of them being scrapings or FNA of primary tumors or head and neck lymph nodes. ${ }^{[16,21,22]}$ Only one case of ENB metastatic to the right parietal scalp was reported in the largest series by Mahooti and Walker. ${ }^{[16]}$

FNA proves to be a safe, cost effective and rapid method for diagnosis of cutaneous/subcutaneous metastasis from internal malignancies. ${ }^{[23,24]}$ To the best of our knowledge, we present the first case of skin metastasis of ENB outside the head and neck region diagnosed by FNA. The cytologic findings of ENB in our case were similar to those described in the literature. Interestingly, Mahooti and Walker observed that ENB, particularly metastatic ENB, does not necessarily contain rosettes or fibrillaryneuropil in cytology specimens. ${ }^{[16]}$ This was true in our case as well. Cytologic findings are therefore non-specific, and in the absence of known history of primary ENB, the differential diagnosis of the tumor would have been broad, and would have included more commonly encountered primary skin tumors as well as metastatic tumor with small round cell morphology. These include but are not limited to lymphoma, basal cell carcinoma, Merkel cell carcinoma, small cell melanoma, rhabdomyosarcoma, Ewing's sarcoma/PNET, and desmoplastic small round cell tumor. Ancillary techniques, including immunostains and molecular studies, should be applied in cases of unknown primary to delineate the origin of the tumor. ${ }^{[14,21-25]}$

Surgery combined with radiotherapy is the most common management which produces the best rates of survival. A long-term follow-up is essential to coordinate treatment and monitor for local recurrence. ${ }^{[20,26-29]}$ In our patient the skin metastasis developed after multimodality therapy and most likely reflected the highly aggressive behavior of this tumor leading to poor outcome. The patient died of the disease several months later.

In conclusion, our case demonstrates that the skin may be a rare site of a metastatic sphenoid sinus esthesioneuroblastoma, and FNA is a reliable diagnostic method of a suspected cutaneous metastasis.

\section{REFERENCES}

1. Berger L, Richard D. [L'esthésioneuroépithéliome olfactif]. Bull Assoc Fr Etud Cancer 1924;13:410. 
2. Broich G, Pagliari A, Ottaviani F. Esthesioneuroblastoma: A general review of the cases published since the discovery of the tumour in 1924. Anti cancer Res 1997;17:2683-706.

3. Svane-Knudsen V, Jorgenson KE, Hansen O Lindgren A, Marker P. Cancer of the nasal cavity and paranasal sinuses: A series of 115 patients. Rhinology 1998;36:12-4.

4. Chacko G, Chandi SM, Chandy MJ. Primary sphenoid and petrous apex esthesioneuroblastoma: Case report. Br J Neurosurg 1998;12:264-6.

5. Mashberg A, Thoma KH, Wasilewski EJ.Olfactory neuroblastoma (esthesioneuroepithelioma) of the maxillary sinus. Oral Surg Oral Med Oral Pathol 1960;13:908-12.

6. Roy A, Timothy J, Anthony R, Chakrabarty A. Correspondence: Aesthesioneuroblastomaarising in pituitary gland. Neuropathol Appl Neurobiol 2000;26:177-9.

7. Morris L, Govindaraj S, Genden EM. Primary sphenoid sinus esthesioneuroblastoma. Am J Otolaryngol 2004;25:350-3.

8. Chirico G, Pergolizzi S, Mazziotti S, Santacaterina A, Ascenti G. Primary sphenoid esthesioneuroblastoma studied with MR. Clin Imaging 2003;27:38-40.

9. Sharma SC, Reddy CE, Srinivasan SS, Rawal A, Singh DP.Isolated esthesioneuroblastoma of sphenoid sinus. Am J Otolaryngol 2002;23:287-9.

10. Lund VJ, Howard D, Wei W, Spittle M.Olfactory neuroblastoma: Past, present, and future? Laryngoscope 2003;113:502-7.

11. Castelnuovo PG, Delù G, Sberze F, Pistochini A, Cambria C, Battaglia P, et al.Esthesioneuroblastoma: Endonasalendoscopic treatment. Skull Base 2006;16:25-30.

12. Dulguerov P, Calcaterra T. Esthesioneuroblastoma: The UCLA experience 1970-1990. Laryngoscope 1992;102:843-9.

13. Resto VA, Eisele DW, Forastiere A, Zahurak M, Lee DJ, Westra WH. Esthesioneuroblastoma: The Johns Hopkins experience. Head Neck 2000;22:550-8.

14. Hussein MR. Skin metastasis: A pathologist's perspective. J Cutan Pathol 2010;37:e1-20.

15. Hyams VJ.Tumors of the upper respiratory tract and ear.In: Hyams VJ, Michaels L, editors. Altas of Tumor Pathology. $2^{\text {nd }}$ series, fascicle 25. Washington DC: Armed Forces Institute of Pathology;1988. p. 240.

16. Mahooti S, Wakely PE Jr. Cytopathologic features of olfactory neuroblastoma. Cancer 2006;108:86-92.
17. Kadish S,Goodman M, Wang CC. Olfactory neuroblastoma: A clinical analysis of 17 cases. Cancer 1976;37:1571-6.

18. Zappia JJ, Bradford CR, Winter PH, McClatchey KD. Olfactory neuroblastoma associated with Kallman's syndrome. J Otolaryngol 1992;21:16-9.

19. Jakumeit HD. Neuroblastoma of the olfactory nerve. ActaNeurochir (Wien) 1971;25:99-108.

20. Faragalla $\mathrm{H}$, Weinberg I. Olfactory neuroblastoma: A review and update. Adv Anat Pathol 2009;16:322-31.

21. Collins BT, Cramer HM, Hearn SA. Fine needle aspiration cytology of metastatic olfactory neuroblastoma. Acta Cytol 1997;41:802-10.

22. Chung J, Park ST, Jang J. Fine needle aspiration cytology of metastatic olfactory neuroblastoma: A case report. Acta Cytol 2002;46:40-5.

23. Gupta RK, Naran S. Fine needle aspiration cytology of cutaneous and subcutaneous metastatic deposits from epithelial malignancies. An analysis of 146 cases. Acta Cytol 1999;43:126-30.

24. Sharma S, Kotru M, Yadav A, Chugh A, Chawla A, Makhija M. Role of fine needle aspiration in evaluation of cutaneous metastasis. Diagn Cytopathol 2009;37:876-80.

25. McCalmont TH. The amazin' mets. Editorial. J Cutan Pathol 2010;37:1196-9.

26. Morita A, Ebersold MJ, Olsen KD, Foote RL, Lewis JE, Quast LM. Esthesioneuroblastoma: Prognosis and management. Neurosurgery 1993;32:706-14; discussion 714-5.

27. Gil-Carcedo E, Gil-Carcedo LM, Vallejo LA, de Campos JM. Esthesioneuroblastomatreatment. Acta Otorrinolaringol Esp 2005;56:389.

28. Jethanamest D, Morris LG, Sikora AG, Kutler DI. Esthesioneuroblastoma: A population-based analysis of survival and prognostic factors.Arch Otolaryngol Head Neck Surg 2007;133:276-80.

29. Folbe A, Herzallah I, Duvvuri U, Bublik M, Sargi Z, Snyderman CH, et al. Endoscopic endonasal resection of esthesioneuroblastoma: A multicenter study. Am J Rhinol Allergy 2009;23:91-4.

Cite this article as: Akinfolarin J, Jazaerly $\mathrm{T}$, Jones $\mathrm{K}$, Abu-Hamdan $\mathrm{M}$, Lonardo F, Folbe A, Giorgadze T. Fine needle aspiration cytology of primary sphenoid sinus esthesioneuroblastoma metastatic to the skin. Avicenna J Med 2012;2:15-8.

Source of Support: Nil, Conflict of Interest: None declared.

\section{Dispatch and return notification by E-mail}

The journal now sends email notification to its members on dispatch of a print issue. The notification is sent to those members who have provided their email address to the association/journal office. The email alerts you about an outdated address and return of issue due to incomplete/incorrect address.

If you wish to receive such email notification, please send your email along with the membership number and full mailing address to the editorial office by email. 